\title{
Efficacy of Majoon Mundi and Roghan Gul in Chronic Plaque Psoriasis - A Case Report
}

\author{
Sabreena Bashir'1 M.A. Quamri², Mohd. Arshad Jamal ${ }^{3}$, Asiya Rashid ${ }^{4}$ \\ ${ }^{1}$ PG. Scholar, Department of Amraz-e-Jild-wa-Tazeeniyat, National Institute of Unani Medicine, Kottigepalya, \\ Magadi Main Road, Bengaluru, 560091, Karnataka \\ ${ }^{2}$ HOD, Department of Amraz-e-Jild-wa-Tazeeniyat, National Institute of Unani Medicine, Kottigepalya, Magadi \\ Main Road, Bengaluru, 560091, Karnataka \\ ${ }^{3}$ Reader, Department of Amraz-e-Jild-wa-Tazeeniyat, National Institute of Unani Medicine, Kottigepalya, \\ Magadi main road, Bengaluru, 560091, Karnataka \\ ${ }^{4}$ PG. Scholar, Department of Ilmul-Advia, National Institute of Unani Medicine, Kottigepalya, \\ Magadi Main Road, Bengaluru, 560091, Karnataka \\ Corresponding Author: Sabreena Bashir
}

DOI: https://doi.org/10.52403/ijrr.20220222

\begin{abstract}
Psoriasis is a skin condition characterized by erythema, clearly delineated papules that are covered with silvery scales. It is a chronic and debilitating disease affecting the quality of life and involves $3 \%$ of world's population. In Unani Classical literature, it is mentioned as Taqashshur-Jild. 28-year-old male was diagnosed with Psoriasis. Patient was treated with Unani drugs Majoon Mundi and RoghanGul. Patient was evaluated before and after treatment using PASI score and DLQI score. Significant improvement was seen in patient after treatment. No adverse effects were observed during and after the study. This case study was done to highlight the efficacy of Unani drugs so as to initiate a step to develop potential herbal-origin drugs for the treatment of Psoriasis.
\end{abstract}

Keywords: Psoriasis, Erythema, Taqashshur-eJild, Unani drugs, PASI score, DLQI score

\section{INTRODUCTION}

Psoriasis is a chronic inflammatory skin disease with a strong genetic base, characterised by complicated epidermal development and differentiation abnormalities as well as various biochemical, immunologic, and vascular abnormalities. ${ }^{1}$ It affects approximately $3 \%$ of the world's population. ${ }^{2}$ Psoriasis prevalence in India ranges from 0.44 percent to 2.8 percent, with a male to female ratio of 2 to $1 .^{3}$ Psoriasis is defined by erythematous, clearly delineated papules and spherical plaques that are covered with silvery or mica-like scales. ${ }^{4}$ It is common, imposes a significant financial burden, and has a severe impact on quality of life due to poor management and social impairment. It's a disease that comes in a variety of morphological forms, with participation ranging from a few affected spots to the entire skin surface. ${ }^{5}$ The condition is characterised by well-defined erythematous plaques with silvery scales that most usually appear on the extensor surfaces of elbows, knees, the lumbosacral area, and the scalp. ${ }^{6}$ Psoriasis is classified in Unani medicine as Dā'uṣ-șadaf, also known as Taqashshur-eJild, and is characterised by dryness, roughness, and the growth of uneven plaques with fish-like scales, as well as itching. ${ }^{7}$ The exact cause of psoriasis is unknown, but it is thought to be multifactorial in nature, with certain environmental factors acting on people who have a specific genetic predisposition, causing immune dysregulation and abnormal keratinization, resulting in the appearance of typical cutaneous lesions. ${ }^{8}$ There are several forms of psoriasis, but 
plaque psoriasis is the most prevalent, accounting for over $90 \%$ of cases. Erythematous, scaly, and symmetrically distributed lesions. In modern medicine, corticosteroids, immune suppressants, phototherapy, and Vitamin-D analogues are used to treat psoriasis, but these treatments are ineffective in the long run due to poor efficacy, rapid relapse, and potential side effects such as osteoporosis, hepatic, and renal failure. ${ }^{6}$ In the absence of a viable solution for chronic plaque psoriasis, it is critical to look for alternatives. In the Unani system of medicine, many Unani drugs are utilised for psoriasis, and many Unani formulations have been tested on psoriasis thus far. Shamim Khan et al. conducted a clinical research in which they examined Psoralia corylifolia Linn and Marham-eGulabi, Unani preparation, in 40 Psoriasis patients and found that they improved overall. ${ }^{9}$ In this case study, the patient was treated with Majoon Mundi and Roghan $G u l$, which are suggested in USM Classical literature for the treatment of Psoriasis.

Patient information: A 28-year-old man presented to the NIUM Bangalore Amrazejild-wa-Tazeeniyat (Dermatology and Cosmetology) OPD with chief complaint of widespread lesions on abdomen, trunk, upper and lower limbs that were accompanied by itching, scaling, and mild erythema on both sides. Plaque lesions with loose scales were present. The size and number of lesions varied, and they were polycyclic in shape with ill-defined borders and symmetrical in distribution. When asked about the same disease, the patient stated that it began gradually and progressed over time, eventually covering a vast region. Patient revealed scales used to shed during itching, and the condition got worse during cold. The patient has been suffering from it for three years.

\section{Diagnostic Assessment:}

The PASI score was used to assess the severity of the lesion, and the DLQI was used to assess the patient's quality of life. Baseline investigations were carried out.
Therapeutic intervention: The patient was subsequently given Majoon Mundi in a dose of $10 \mathrm{gm}$ twice daily orally, as well as Roghan-Gul for local application. Before and after therapy, photographs of lesions were obtained.

Informed consent: A written informed consent was obtained prior to the intervention

\section{Follow-up and Outcomes:}

The typical features of lesions were observed throughout the treatment period, and there was a considerable improvement in lesions in terms of erythema, scaling, and induration. Furthermore, the $\mathrm{PASI}^{10}$ and DLQI ${ }^{11}$ scores were assessed on $\left(0^{\text {th }}, 14^{\text {th }}\right.$, $28^{\text {th }} \& 42^{\text {th }}$ days of follow-ups). PASI and DLQI scores reduced dramatically from 31.6 and 18 at baseline to 8 and 6 at the end of the treatment period respectively. On the $42^{\text {th }}$ day of treatment, significant changes were observed. During the entire period of treatment, no side effects were observed.

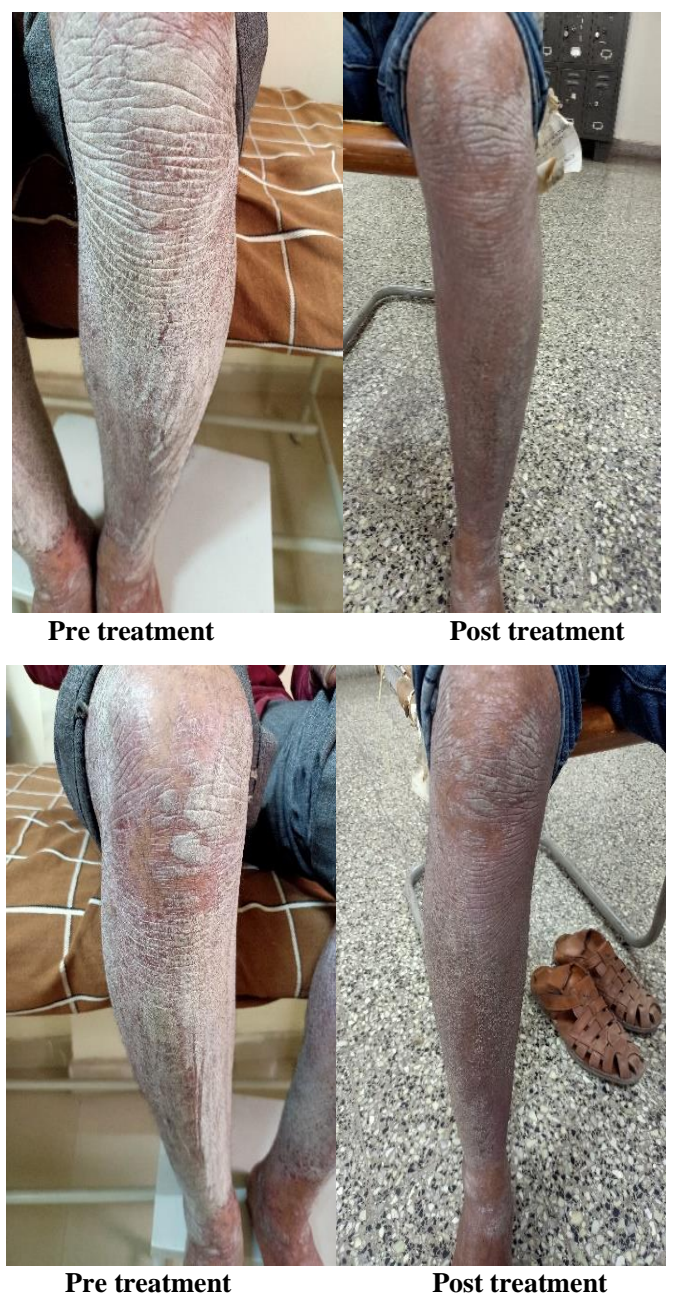



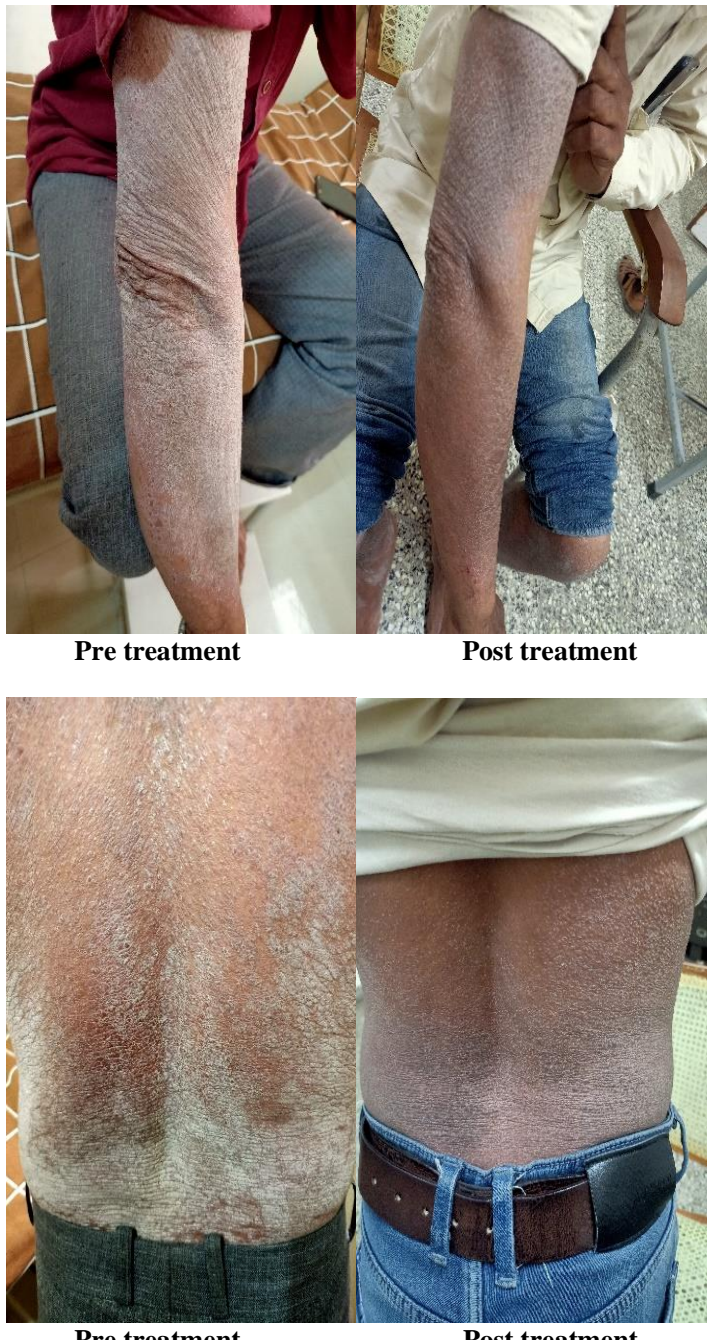

Pre treatment

Post treatment

\section{DISCUSSION}

The therapeutic properties of Majoon Mundi and Roghan Gul are responsible for the above-mentioned considerable results. Mundi has been shown to have anti-psoriatic properties in several in vitro and in vivo pharmacological studies. These anti-psoriatic effects are achieved by anti-inflammatory and anti-proliferative activity in keratinocytes and immune cells. ${ }^{12}$ A clinical trial is underway with the same drug in Chronic Plaque psoriasis patients to find its efficacy on large scale.

\section{CONCLUSION}

Based on the outcome of the single case observation it can be concluded that Unani drugs have a great potential in treating diseases. In the conventional system of medicine, although there are a variety of treatment options but due to the chronic nature of the disease, it is suggested that the treatment be taken for a long time, which can lead to long-term side effects and an increased risk of non-compliance. In addition, the treatment is expensive. Unani medicines are least toxic, cost-effective, and efficacious; thus, they can be used to treat Psoriasis-like disorders. There is an increasing demand for natural-origin medicines in the modern period, therefore, there is a strong desire to perform largescale randomised clinical studies to assess efficacy and safety of Unani drugs.

\section{Acknowledgement: None}

\section{Conflict of Interest: None}

\section{Source of Funding: None}

\section{REFERENCES}

1. Fitzpatrick,Goldsmith LA et al. Dermatology in general medicine. 8th ed. Medical publication division Mc Graw Hill; 2012: p. 197.

2. Dogra S, Mahajan R. Psoriasis: Epidemiology, clinical features, comorbidities, and clinical scoring. IDOJ. Nov-Dec 2016; 7(6): p. 471.

3. Dogra S, Yadav S. Psoriasis in India: Prevalence and Pattern. Indian Journal of Dermatology, Venereology, and Leprology. 2010 Nov1;76(6): p 595.

4. Longo DL, Fauci AS, Kasper DL, Hauser SL, Jameson JL, Loscalzo J.Harrison's principles of internal medicine. Vol 1.18th ed. USA: McGraw Hill companies;2012: p 398.

5. Sams WM, Lynch PJ. Principles and Practices of Dermatology. 2nd ed. Churchill Livingstone;1996: p 341.

6. Burns T, Breathnach S, Cox N, Griffiths C. Rook's textbook of dermatology Vol 1.8th ed. Wiley-Blackwell;2010: p20.1.

7. Ibn-e-sina. Al-Qanoon fit Tib (Arabic). Vol4. New Delhi: Institute of History Medicine and Medical Research; 1408 Hijri: 305-306.

8. Ghosh A, Panda S. Recent understanding of the etiopathogenesis of Psoriasis. Indian Journal of Pediatric Dermatology.JanMar2017;18(1): p1.

9. M. Shamim Khan, MM.H Siddiqui \& Shagufta Aleem. Effect Psoralia corylifolia 
Linn and Marham-e- Gulabi in Da-al Sadaf (psoriasis). Indian Journal of Traditional Knowledge. July 2009;8(3): 425-430.

10. Haider S, Wahid Z, Najam-us-Saher, Raiz F. Efficacy of Methotrexate in patients with plaque type psoriasis. Pak J Med Sci 2014;30(5):1050-1053.

11. Finlay AY and Khan GK. Dematology Life Quality Index (DLQI): a simple practical measure for routine clinical use .Clin Exp Dermatol 1994;19;210-216.

12. Chakrabarti D, Suthar A, Jayaraman G, Muthuvelan B, Sharma S, Padigaru M.
NPS31807, a Standardized Extract from Sphaeranthus indicus, Inhibits Inflammatory, Migratory and Proliferative Activity in Keratinocytes and Immune Cells. Journal of Pharmacology \& Pharmacy. April 2012;(3):187

How to cite this article: Sabreena Bashir, M.A. Quamri, Mohd. Arshad Jamal et.al. Efficacy of majoon mundi and roghan gul in chronic plaque psoriasis- a case report. International Journal of Research and Review. 2022; 9(2): 156-159. DOI: https://doi.org/10.52403/ijrr.20220222 